\title{
Paul Valéry: paradojas y desafios del arte en el sistema económico moderno
}

\author{
John Ramirez Jaramillo \\ Universidad de Antioquía
}

Resumen: Este artículo busca demostrar que el pensamiento de Paul Valéry desarrolla un análisis crítico de las condiciones en que el arte establece su relación con el sistema económico moderno. Para validar dicha hipótesis, inicialmente es presentada la noción de "máquina económica", con la que es descrita la teoría de la economía, y son definidas las características de los objetos útiles e inútiles que componen el mercado. A su turno, el artículo detalla el proceso histórico de la mercantilización del arte en la época moderna, y aclara las razones por las cuales los productores y consumidores de obras artisticas asumen una forma de apropiación diferente hacia estas. Se prueba que, debido a la primacía de la naturaleza simbólica de la obra artística, la generación y actualización de su valor cuantitativo y cualitativo se enfrenta a un alto grado de indeterminabilidad. También se demuestra la existencia de una teoría estética argumentada con la que el autor francés propone la apreciación del valor de la obra. Por último, es descrito el papel que debe asumir la crítica ante la producción artística destinada para el consumo social.

Palabras clave: máquina económica; obra artística; productor; consumidor; valor artístico

\begin{abstract}
Paul Valéry: Paradoxes and Challenges of Art in the Modern Economic System". The aim of this article is to demonstrate that Paul Valery's thought develops a critical analysis of the conditions in which art establishes a relationship with the modern economic system. In order to validate this hypothesis, the notion of "economic machine", which describes the economic theory and defines characteristics of useful and useless objects that constitute the market, is presented. Afterwards, the article details the historical process of commercialization of art in modern times and clarifies the reasons why art producers and consumers appropriate the work of art in different forms. It is shown that, due to the supremacy of the symbolic nature in the work of art, the creation and actualization of its quantitative and qualitative value conveys a great deal of indeterminability. The article also demonstrates the existence of an aesthetic theory with which the French author proposes the appreciation of value of the work of art. Finally, the role that critique should assume regarding artistic production dedicated to social consumption is described.
\end{abstract}

Key words: economic machine; artistic work; producer; consumer; artistic value 


\section{Introducción}

El presente escrito estudia las paradojas y desafios que, de acuerdo al pensamiento de Paul Valéry, se desprenden del proceso de intercambio y valorización del arte moderno en el momento en que hace su ingreso irreversible dentro del sistema de la economía capitalista. Este es un tema rico y a la vez complejo, al igual que muchos de los otros temas que nutren la sugestiva teoría estética en cuestión. Por ello, resulta indispensable partir de la teoría económica con la que el autor francés interpreta la modulación de las relaciones del mundo social. De hecho, cabe destacar que las formas de producción y consumo de los bienes materiales que dan sustento a los seres humanos y que favorecen el desarrollo de las sociedades constituyen, para Valéry, el punto de referencia analógico a través del cual instaura los fundamentos de una suerte de economía denominada por él mismo como "economía poética". Esta economia se halla conformada por todas las obras que han sido producidas por los artistas e intelectuales en general y que circulan en los distintos espacios de la cultura ensanchando, cada una con un aporte nuevo para el conocimiento, el capital espiritual de cada civilización.

Ahora bien, para entender la forma en que se organizan las relaciones de intercambio entre quienes ofrecen esta clase de productos y quienes necesitan proveerse de ellos, merece la pena iniciar el siguiente parágrafo explicando aquello que el autor de El método de Leonardo entiende por "máquina económica", a la par que detallamos la apreciación acerca de los objetos útiles e inútiles que alimentan el sistema de funcionamiento de dicho dispositivo.

\section{La máquina económica y las características de sus objetos útiles e inútiles}

La obligación de responder a las adaptaciones del medio y satisfacer las necesidades más esenciales ha llevado al hombre a implementar toda una serie de acciones valoradas según su grado de contribución en el desempeño de las 386 funciones vitales. Con un ejemplo muy conciso, Valéry ilustra la eficiencia de aquella clase de operaciones mediante las cuales los seres humanos aseguran un ahorro respecto a tiempos de cuidado y gastos de energía cada vez que realizan una actividad vital específica: "las suelas economizan la atención de no herirse caminando"1. Históricamente hablando, esta búsqueda de previsión y eficacia ha

1 Valéry, P., Cahiers I, París: Gallimard, 1973, p. 968. 
dado paso a la instauración del mundo económico con sus formas de producción, distribución, circulación y consumo de objetos y bienes. El autor de Miradas al mundo actual constata que el instinto de sobrevivencia y la búsqueda de acciones útiles coordinadas llevada a cabo por el hombre constituyen los resortes que han determinado el surgimiento y desarrollo del engranaje económico: "El hombre actúa para calmar esta sensación [de escasez y carencia]: y su acción, desarrollada, organizada, coordinada, extendiendo su radio a millares de seres y a la superficie del globo, ha dado nacimiento a toda la máquina económica" 2 . Aun cuando pueda parecer un contrasentido, por "máquina económica" debemos entender algo que va más allá de la idea de unos procesos de producción y consumo sujetos a una lógica organizativa inflexible, ciega y rutinaria ${ }^{3}$. Pues, si bien es cierto que el funcionamiento de la economía lo determinan las acciones organizadas y cíclicas generadas por la oferta y demanda de mercancias, esto no significa que su dinámica esté libre de imprecisiones, cambios y rupturas impredecibles. De hecho, las presiones sociales, las competencias desleales, las imposiciones políticas y económicas y, en caso extremo, los conflictos bélicos, constituyen factores que pueden afectar en cualquier momento el equilibrio económico. Por otro lado, cuando Valéry indica que la máquina económica es "una amplificación colosal del organismo", está queriendo recalcar que la gigantesca red de acciones que conforma el mundo

2 Valéry, P., OEuvres II, París: Gallimard, 1960, pp. 1070-1071.

3 Valéry emplea la palabra "máquina" en numerosas ocasiones para referirse a los aspectos funcionales que se encuentran en todo sistema y ciclo de orden natural y artificial que integran el mundo. De acuerdo con su pensamiento, la explicación que intentemos dar de cualquier cosa -la sociedad, la conciencia, el lenguaje, el arte, etcétera-implica razonar sobre su funcionamiento y sus limitadas modificaciones cíclicas, así como sobre las relaciones y divergencias de los elementos que la configuran (Schmidt-Radefeldt, J., Paul Valéry linguiste dans les Cahiers, París: Klincksieck, 1970, p. 12). En lo que respecta al análisis de la naturaleza viviente, por ejemplo, es notorio observar el modo en que este autor construye un penetrante análisis de su organización y funcionamiento, asi como de sus operaciones y acciones recurrentes, fijando dicho paralelo. No obstante, es necesario aclarar que la idea de máquina pensada por Valéry se concibe a partir de una organicidad sistemática, identificada por su capacidad de transformación, autoconservación y operatividad cíclica, y no desde un punto de vista de operatividad y cálculo puramente rutinario. Precisamente, una de las críticas dirigidas contra Descartes obedece a su pretensión de igualar el funcionamiento del mundo viviente con el funcionamiento automatizado e invariable de una máquina. Es por este motivo que, en el momento de establecer la comparación entre el desempeño del animal y la máquina artificial, Valéry hace la siguiente precisión: " $\mathrm{El}$ animal no es ciertamente una máquina, en el sentido que Descartes podía concebir una máquina. Pero la idea de máquina se ha modificado. Sabemos producir otras transformaciones dirigidas distintas de aquellas de las cuales Descartes podia tener idea... Lo que queda es que un animal solo tiene un número finito de posibles respuestas para las circunstancias; que su vida orgánica es cíclica" (Valéry, P. Cahiers II, Paris: Gallimard, 1974, pp. 758-759).

4 Valéry, P., Miradas al mundo actual, Buenos Aires: Losada, 1954, p. 175. 
económico es una especie de sistema viviente determinado por operaciones cíclicas organizadas que buscan su propia regulación, adaptabilidad y conservación general. Ello es visible por la manera en que son definidos los ritmos de producción, la fijación del precio de las mercancías, la delimitación del tipo de servicios ofrecidos, al igual que por el pago de salarios, el cobro de rentas e intereses y demás acciones reguladoras que allí son ejercidas.

Debido a que el arte es un elemento singular integrado dentro del sistema económico, Valéry detalla su particularidad reconociendo la diferencia que hay entre los objetos útiles e inútiles que ingresan como mercancías para el consumo social. Atendiendo a este contraste, es indispensable recordar que el mundo económico posee unas condiciones de operatividad sin las cuales no sería posible la interacción eficiente y productiva del intercambio entre productores y consumidores. Estas condiciones son concretadas por la relación existente entre la necesidad que tienen los hombres de acceder a aquellos objetos y servicios imprescindibles para el desempeño normal de su vida, y la posibilidad real que hay de producirlos y ofrecerlos.

En vista de que el sistema económico está guiado por la búsqueda del máximo rendimiento, sus acciones y dispositivos de intercambio tienden a proveer principalmente aquellos objetos de carácter eminentemente útil, es decir, aquellos objetos que son de amplio uso humano por cuanto, como precisa Léon Walras, autor leído por Valéry, "responden a una necesidad cualquiera y permiten su satisfacción" . Por contrapartida, los objetos inútiles son aquellos que escapan a una apropiación social generalizada debido a que no poseen un valor de uso determinante (como sí es el caso de la alimentación, el vestido, la vivienda, la seguridad social, etcétera), o bien porque su elaboración no alcanza un valor que los haga productivos. Es por este motivo que el funcionamiento del sistema económico no los ingresa, al menos con tanta facilidad, como mercancía con un valor de cambio en sus procesos de oferta y demanda ${ }^{6}$. Precisamente, este es el obstáculo que enfrenta la mercantilización de las llamadas por Valéry "producciones inútiles de la mente" o producciones intelectuales. Estas, como él mismo explica, forman parte de "aquellos objetos y servicios que solo satisfacen deseos, y no necesidades absolutas, y que solo corresponden a disposiciones individuales y no a funciones vitales"7.

\footnotetext{
5 Walras, L., Éléments d'économie politique pure, ou Théorie de la richesse sociale, París: R. Pichon et R. Durand-Auzias, 1926, p. 21.

6 Cf. Marx, K., El Capital. Crítica de la economía política, v. I, México D.F.: FCE, 1974.

7 Valéry, P., Miradas al mundo actual, p. 176.
} 
Las producciones inútiles de la mente están conformadas por todas las obras derivadas del campo de la ciencia, el arte, la literatura y la filosofia, las cuales no otorgan al hombre ningún beneficio material directo por estar privadas de cualquier finalidad práctica que incremente los intereses de lucro del sistema económico. Lo que no deja de ser paradójico es que esta clase de creaciones inútiles, tomadas desde el punto de vista material, prestan un inestimable servicio en favor del incremento de la cultura humana ${ }^{8}$. Valéry explica este aporte tanto desde el terreno individual como social. En cuanto al primero, estipula que cada una de aquellas producciones habilita al individuo para conquistar su subjetividad al mostrarle sendas a través de las cuales puede ejercitar autónomamente su propia autoconciencia. En la medida en que, a decir suyo, se trata de una forma de creación que "procede directamente de lo íntimo del hombre" y, como tal, se dirige "a lo intimo del hombre" 9 , cada obra intelectual contribuye de forma activa y profunda al reconocimiento y modelación de la conciencia singular humana. Con respecto al segundo ámbito, considera que su contribución consiste en permitir indagar y desarrollar "la capacidad de mutua comprensión entre los hombres que es, después de todo, el fundamento necesario de toda sociedad"10.

Guiado por la teoría económica de Marx, Valéry introduce -como ya lo habiamos anunciado desde un inicio- un paralelo entre la historia del intelecto y la historia económica, al entender aquella como un proceso de producción y consumo de obras ${ }^{11}$. Tal convergencia vendría justificada por las relaciones de dependencia que guarda la superestructura social, representada por todas las formas de organización política, religiosa, cultural y artística, con respecto a la infraestructura económica, ordenada, a su vez, por los distintos medios y fuerzas de producción que solventan la vida material de los individuos. De aquí se deduce que la producción y el consumo de las obras del intelecto están sometidos también a unas leyes de valorización y fluctuación ${ }^{12}$. Dado que en el

\footnotetext{
8 Como lo recuerda Juan Acha, desde el punto de vista de la teoría materialista, la cultura está conformada, de una parte, por un elemento material relacionado con todas las actividades de producción, distribución y consumo de bienes destinados para la subsistencia directa de una sociedad; de otra parte, por un elemento espiritual que vincula todas aquellas actividades encaminadas a producir, distribuir y consumir bienes culturales cuyo objeto principal se centra en la formación y el desarrollo de la conciencia de los miembros de una sociedad ( $C f$. Acha, J., Crítica del Arte. Teoria y práctica, México D.F.: Trillas, 1992, p. 21).

9 Valéry, P., Vues, París: La Table Ronde, 1948, p. 91.

10 Ibid.

11 Cf. Bucher, J., Paul Valéry y la nueva crítica literaria, Cali: Universidad del Valle, 1979, pp. 104-105.

${ }^{12}$ En su ensayo La libertad del espíritu, Valéry denuncia la baja crucial que en su época sufren los valores de la mente. Allí establece, a través de la imagen de la bolsa de valores, el paralelo
} 
rango de dicha clase de objetos ocupa un destacadísimo lugar todo el conjunto de las obras artísticas producidas en la época moderna, merece la pena rastrear el modo como el autor de El alma y la danza describe los conflictos, paradojas y retos que estas últimas deben enfrentar al ingresar dentro de las dinámicas de la producción y consumo de la sociedad capitalista.

2. La mercantilización de los productos artísticos y la divergencia de intereses entre productores $y$ consumidores

El proceso de transformación social vivido por Europa desde el fin del período medieval viene afianzado por el crecimiento gradual del sistema de ofertas y demandas que propicia la conformación de un complejo mercado encargado de suplir los deseos y las necesidades, cada vez más variadas, del individuo moderno. El desarrollo de este sistema de intercambio económico basado en la división social y técnica del trabajo -por el cual se reemplaza el antiguo modelo de las relaciones productivas de la época feudal ${ }^{13}$ - incorpora una nueva lógica en la que prima la eficiencia y la búsqueda de lucro. La implementación del modelo mercantilista (extendido con mayores implicaciones a partir de la Revolución Industrial) transformó a tal punto los modos de relación social y económica que, desde entonces, estos se establecieron dentro de dos líneas principales de rango correlacionadas entre sí: la de los productores y los consumidores. Esta nueva forma de vínculo hizo que se aplicara instintiva y continuamente la fijación de precios, la relación entre la oferta y la demanda frente a todo lo producido, incluyendo las obras artísticas.

En lo que concierne al proceso de mercantilización del arte, ya desde la Baja Edad Media y el Renacimiento es visible su explotación comercial. Este fenómeno se visibiliza por la creciente demanda de obras artísticas solicitadas y pagadas por clientes adinerados, pertenecientes a las instituciones eclesiásticas, aristocráticas y burguesas. Vale la pena agregar que la ampliación y el éxito del mercado del arte a partir del siglo XVII permitieron que los artistas no solamente se dedicaran a trabajar los géneros que el público demandaba, 390 sino que significó también la posibilidad de que experimentaran nuevas formas de creación, siguiendo sus propias intuiciones y necesidades de expresión, como lo demuestran Rembrandt en el siglo XVII y Goya a finales del XVIII.

entre los valores de orden intelectual y los valores materiales con el objetivo de mostrar la situación vulnerable y precaria a la que están sometidas las creaciones de la cultura en un mundo gobernado cada vez más por los intereses de producción y ganancia material.

${ }_{13}$ Cf. Hilton, R. y M. Dobb, La transición del feudalismo al capitalismo, Barcelona: Crítica, 1977. 
Aun cuando es cierto que el sistema del mercado artístico se pliega allí a las condiciones propias del comercio, la valoración de las obras está todavía sujeta a las apreciaciones y los controles de una crítica académica institucionalizada que dictamina qué obras y artistas merecen o no la aprobación del público. Los Salones de París del siglo XIX, con su famosa sección de los Rechazados, testimonian la importancia detentada por el jurado oficial para aprobar o denegar la calidad de los artistas y las producciones que presentaban con el ánimo de ser expuestas y reconocidas. Así, por ejemplo, es sabido que el Almuerzo sobre la hierba de Manet fue despreciado por esta crítica oficial y se exhibió en el Salón de los Rechazados. No obstante, el suceso que testimonia el irreversible ingreso del arte en la órbita de la comercialización capitalista se da con el relevo que el mercado artístico francés hace, desde la década de 1870, de las funciones organizativas de la vida artística liderada antes por la Academia ${ }^{14}$. Puesto que la crítica institucionalizada, encabezada por los jurados oficiales de los Salones, no garantizaba un entorno seguro para la evolución del arte, se instalaron los salones no oficiales a la par que se implementó la figura del marchante, concebido como un agente encargado de comerciar y promocionar las nuevas promesas artísticas. De este modo, con la consolidación del mercado económico y el incremento de la productividad impulsada por las políticas liberales finiseculares, la producción artística sufre una enorme modificación, a tal punto que aprende a adaptarse con un mayor nivel de conciencia estratégica a las leyes de la oferta y la demanda, al requerimiento de obras impulsado y pactado por el gusto reinante.

La complejidad del mercado artístico de la época moderna es analizada atentamente por Valéry, aplicando para ello las ya mencionadas nociones económicas de producción y consumo. En este caso, al artista le otorga el rango de productor, a la obra la categoria de producción, en tanto que el lector, auditor o espectador de dicha obra es subsumido "bajo el nombre económico de consumidor"15. La pretensión de introducir estas tres categorías reside, principalmente, en distinguir las diferencias de ideas e intereses que vinculan al artista y al espectador en relación con la obra artística. Esto lo expresa el autor francés al señalar: "es imposible reunir en un mismo estado y en una misma consideración, la observación del espíritu que produce la obra y la observación del espíritu que produce algún valor de la obra"16. De esta manera, prueba que

\footnotetext{
${ }^{14}$ Cf. Moulin, R., Le marché de la peinture en France, Paris: Minuit, 1967.

${ }^{15}$ Valéry, P., Teoría poética y estética, Madrid: Visor, 1990, p. 110.

16 Ibid., p. 112.
} 
el productor y el consumidor operan con un sistema de apropiación diferente: mientras el primero -el artista- analiza la obra mediante una capacidad de abstracción y cálculo, teniendo en cuenta todos los elementos de carácter formal y de contenido que participan en su construcción, el segundo -el espectador- la analiza poniendo en juego su capacidad de inducción, impulsado por el placer sensible e imaginativo que despierta la obra ${ }^{17}$.

A esto se suma que mientras el productor puede gastar un número considerable de meses o años preparando, revisando y puliendo la obra, el consumidor se apropia de ella y experimenta sus efectos en pocos instantes: "Una ojeada bastará para apreciar un monumento considerable, para experimentar el choque"18. Así, la experiencia de los efectos artísticos se realiza sin necesidad de conocer los esfuerzos llevados a cabo por el productor, algo que demuestra la falta de correspondencia y la independencia que hay entre ambas actividades. Valéry corrobora esta diferencia apropiativa al indicar que "las ideas que uno y otro se hacen de la obra son incompatibles"19. Con miras a entender el desarrollo de las posibilidades evolutivas del arte y la comprensión de sus efectos estéticos, recalca la importancia de identificar y separar los alcances de ambas actividades y no tratarlas en directa correspondencia: "Únicamente podemos considerar la relación de la obra con su productor, o bien la relación de la obra con aquel a quien ella modifica una vez realizada. La acción del primero y la reacción del segundo no pueden confundirse nunca" ${ }^{20}$. A esto debemos agregar la singularidad con la que se despliegan los intereses de la producción y el consumo del arte. Ello se debe a que, conforme sea la naturaleza del individuo que ejerce uno u otro papel, así como el contexto histórico y social dentro del cual se desenvuelve, la creación de los efectos artísticos supondrá siempre un reto, a la par que su recepción conllevará una dificil predicción.

\footnotetext{
${ }^{17}$ Valéry explica en los siguientes términos estas dos formas opuestas de asimilación de la obra artística: "la obra de arte se construye mediante una abstracción, y esta abstracción es más o menos enérgica, más o menos fácil de definir, según que los elementos tomados de la realidad sean fragmentos de esta más o menos complejos. Por el contrario, toda obra de arte se aprecia gracias a una especie de inducción por la producción de imágenes mentales, y esta producción también debe ser más o menos enérgica, más o menos fatigosa, según lo solicite un simple almocárabe en un vaso o una frase quebrada de Pascal" (Valéry, P., Escritos sobre Leonardo da Vinci, Madrid: Visor, 1987, p. 48).

${ }^{18}$ Valéry, P., Teoria poética y estética, p. 113.

19 Ibid. En una línea de apreciación próxima a la de Valéry, el poeta y ensayista inglés W. H. Auden apoya este planteamiento al afirmar: "Los intereses de un escritor y los de sus lectores no coinciden jamás, y si lo hacen, solo puede tratarse de un afortunado accidente" (Auden, W.H., El arte de leer. Ensayos literarios, Barcelona: Lumen, 2013, p. 25).

${ }^{20}$ Valéry, P., Teoría poética y estética, p. 113.
} 
De esta divergencia de horizontes se desprenden dos categorias de valoración de las obras artísticas que van a guiar el análisis de su propio mercado. Una estará determinada simplemente por el tipo de efectos placenteros que el consumidor busca en la obra (un lector compra un libro de acuerdo con el género o el autor que más le llama la atención, mientras que un espectador elige comprar la boleta para la película que encuentra más llamativa, otro tipo de público que toma la decisión de ir al museo o al teatro, según las expectativas de su gusto estético, etcétera). A otra categoría de valoración de la obra artística se centra en el análisis e interpretación de su hacer. Es claro que aquí convergen, en primerísimo lugar, los intereses reflexivos del propio artista, pero también los de otros artistas, así como los de especialistas y críticos que están atentos a estudiar de forma discriminada el valor de la obra. De alguna manera, en este renglón se integran los demás representantes de la industria cultural que buscan explotar, de acuerdo con sus propios intereses, los efectos artísticos que más puede demandar el público masificado. Valéry resume estos dos rangos de apreciación del arte en los siguientes términos: "Las obras de arte solo tienen interés $1^{\circ}$ voluptuoso (consumo) $2^{\circ}$ técnico (producción)" ${ }^{21}$.

Esta clasificación de intereses establecida entre productores y consumidores va a permitir discernir y ordenar con un mayor grado de objetividad el desarrollo de las nuevas propuestas artísticas teniendo en cuenta, por un lado, los nuevos gustos individuales y colectivos que complejizan el mundo de la cultura, lo que vincula el estudio de grupos poblacionales, con sus tendencias, imaginarios, preocupaciones, etcétera; y por otro lado, tomando en consideración las nuevas propuestas conceptuales, así como las nuevas experimentaciones formales ofrecidas por los artistas.

A la luz de esta evolución de las relaciones del mercado del arte, es importante resaltar la ampliación que desde el siglo XIX se da del consumo artístico con el ingreso de los medios de reproductibilidad técnica y el crecimiento de la población alfabetizada. Impulsadas por estos nuevos fenómenos, las dinámicas de intercambio y de demanda crecientes de los distintos géneros artísticos en la época moderna obligaron a que el proceso de producción y consumo del arte desarrollara un sistema de correspondencia mucho más integrado de lo que hasta entonces se había podido alcanzar ${ }^{22}$. Valéry registra esta transformación

\footnotetext{
21 Valéry, P., Cahiers II, p. 1053.

22 A manera de breve contextualización, cabe aclarar que ya desde el siglo XVIII, paralelamente al advenimiento de los escritores independientes que modifican el modo de hacer literatura, surge la figura de un nuevo público lector que demanda de manera ávida este nuevo tipo de géneros y
} 
y ajuste organizativo que ha comportado el incremento del consumo artístico: "La producción y el consumo de arte han dejado de ser completamente independientes una de otro. Tienden a organizarse"23. Es válido acotar que, en la actualidad, el proceso organizativo por el cual se ha estructurado el sistema económico del arte ha permitido no solo que la profesión de artista (con todas las dificultades que, no obstante, aún debe enfrentar) sea socialmente reconocida, sino que ha favorecido también el surgimiento de instituciones, la formación de gestores y críticos, la búsqueda de patrocinadores e intermediarios, la implementación de estrategias de mercado, así como la creación de reglamentos y protocolos para la conservación de las obras, sin lo cual no sería posible la promoción, difusión, adquisición y conservación del capital artístico y cultural. La gestación de este nuevo ordenamiento que le permite al arte acompasarse con las dinámicas que alcanzan la época actual es percibida por Valéry: "El Arte tiene su prensa, su politica interior y exterior, sus escuelas, sus mercados y sus bolsas de valores; tiene incluso sus grandes bancas de depósito, a las que van progresivamente a acumularse los enormes capitales que han producido de siglo en siglo los esfuerzos de la 'sensibilidad creadora', museos, bibliotecas, etc." 24 . Estos argumentos ponen en evidencia la conciencia de que el trabajo artístico en el contexto de la modernidad ha superado muchos de los obstáculos que antes impedían su amplia posibilidad de intercambio social y que, en no pocos casos, lo condenaban a ser una actividad netamente improductiva.

Asimismo, el poeta francés considera que la obra artística debe ser tomada como una mercancía destinada para el consumo. Desde esta perspectiva, estima que todas las acciones y aspectos directos e indirectos que intervienen en la construcción de la obra -la documentación, las lecturas, la visita de lugares diversos, el desarrollo de ensayos y experimentaciones que conducen al producto

creaciones en la poesía, el teatro y la novela. Como lo advierte Werner Faulstich, la conjunción de ambos estratos formaría las bases del futuro mercado literario ( $C f$. Faulstich, W., "La literatura como mercancía. Sobre el efecto fascinador de la comercialización de la literatura en la sociedad burguesa”, en: Wischer, E. (ed.), Historia de la literatura. Vol. V. La Edad Burguesa: 1830-1914, Madrid: Akal, 1993). No obstante, es en el siglo XIX que este nuevo mercado empieza a configurarse convirtiendo el libro en una mercancía y la producción, distribución y recepción de la literatura en un proceso que va ganando mayor consolidación. Desde esa época, los escritores aprenden a adaptarse a las diferentes condiciones de comercialización de sus obras, a las innovaciones técnicas, al papel selectivo del editor, al surgimiento y desarrollo de una crítica (aparecida en suplementos, revistas y gacetas) que, gradualmente, se incorpora a la economía del nuevo mercado literario, encargándose de difundir las nuevas producciones y de preparar e instruir, a su vez, a un público lector apto para el consumo de dichas obras. En el apartado final de este escrito veremos la consideración que tiene Valéry sobre el papel ejercido por dicha crítica.

${ }^{23}$ Valéry, P., Teoría poética y estética, p. 200.

24 Ibid., p. 201. 
final-forman parte de aquellos insumos que cualifican su valor como producto de intercambio. Valéry se aleja de la concepción de un arte autónomo que pretende solo expresar la voluntad creativa del artista y que toma la obra como algo absolutamente contrario a un objeto utilitario. Si bien admite que en la realización de la obra artística se genera un espacio único para la afirmación de la autonomía del ser singular, por el cual se posibilita una vía de máximo aprendizaje para el perfeccionamiento del yo, igualmente es consciente de que su "inútil utilidad" cobra real sentido cuando ingresa como capital cultural de consumo en la red de los intercambios sociales, independiente del público masificado o selecto al cual vaya a llegar. Esto es lo que motiva el siguiente aforismo: "Si 'el acto de comercio' es comprar con la intención de revender, comerciante es el artista o el autor que observa, viaja, lee y casi que existe únicamente en el perfil de producir - volver a poner sobre el mercado su impresión - No adquirir para sí - Pero, acaso, ¿adquirir para sí tiene algún sentido?”25.

Los anteriores argumentos demuestran que el arte, para su propia existencia y sobrevivencia en el mundo moderno, necesita movilizarse como una mercancía más dentro de los sistemas de intercambio establecidos por el "colosal organismo de la máquina económica”. Sin embargo, dicho proceso comporta para Valéry otra serie de paradojas y dificultades que es menester analizar.

\section{La finalidad del objeto artístico}

Así como Valéry se preocupa por definir un concepto general del arte pensándolo desde la dimensión misma del hacer ${ }^{26}$, también procura especificar su significado abordando la finalidad de dicho hacer. Con esto pone nuevamente en una relación inextricable de complementariedad la producción y el consumo del arte. Específicamente, enseña que la finalidad de la obra artística (sea un poema, una novela, una pintura, una obra musical, un filme, una representación escénica, etcétera) consiste en generar efectos que exciten la sensibilidad, reflexión e imaginación del público. Estos efectos, en tanto que

\footnotetext{
${ }^{25}$ Valéry, P., OEuvres II, p. 622.

${ }^{26}$ En su ensayo Noción general del arte, Valéry plantea el significado del arte tomando como punto de partida el origen etimológico de dicha palabra. Por esta vía constata que, en su acepción más antigua y amplia dada por el término griego technē, la palabra "arte" señala una manera o particularidad de hacer cuya práctica compromete, invariablemente, un juicio discriminatorio y selectivo ajustado a unos fines de productividad. De igual modo, resalta la íntima relación que guarda el concepto de poética con la palabra "hacer", en la medida en que el componente de lo fáctico se visibiliza en todos los procesos, los métodos, los ordenamientos y las discriminaciones que participan en la creación de la obra.
} 
son de orden estético, se caracterizan por despertar un placer perceptivo que incita a ser ampliamente prolongado o renovado, que es tanto más cuando lo ofrecido por dicha obra suscita en el espectador múltiples emociones, así como inacabables interpretaciones y juegos de asociaciones imaginativas. Este tipo de impresión por el cual, verbigracia, deseamos leer nuevamente el verso de un poema, repetir el capitulo de una serie televisiva o escuchar otra vez una canción cualquiera, es identificado como un "infinito estético"27.

A diferencia de las posturas estéticas concebidas desde el romanticismo que defienden la realización de un arte puro donde cuenta solo la libertad del artista, Valéry estima que el arte cobra sentido cuando sus potencialidades son desplegadas pensando en el impacto positivo que puede generar su recepción, no importando la condición y grado de refinamiento intelectual de las personas a las cuales alcanza a llegar: "El objeto de un arte no puede ser sino producir algún efecto feliz sobre personas desconocidas, ya sean las más numerosas o las más delicadas que quepa imaginar..."28. Aunque el artista construye las obras queriendo invariablemente desarrollar su capacidad de invención y su propia originalidad, el mérito de toda obra no reside precisamente en que ella muestre el egotismo del artista que la gestó ${ }^{29}$ pues, por encima de la más profunda autorreferencialidad que pueda obtenerse y de la búsqueda de los limites de control y perfeccionamiento del propio yo del artista, lo que cuenta en la realización de una obra es la potenciación del vínculo que, finalmente, alcance a establecer con el público hacia el cual va dirigida en tanto proyecto culminado. Ello exige, por parte de su realizador, un proceso de estudio y contextualización que permita aprender a integrar e identificar el gusto de los

27 Cf. Hytier, J., La poétique de Valéry, París: Armand Colin, 1970, p. 232.

${ }^{28}$ Valéry, P., Variedad II, Buenos Aires: Losada,1956, p. 235.

29 Es sabido que Valéry otorga un papel central al cultivo del yo. Esta búsqueda del mayor grado de perfección consciente de sí mismo, la denomina egotismo. Según su criterio, el egotismo surge de un sentimiento irreductible de diferencia que es propio de las personalidades fuertes que rechazan y temen reconocerse como un individuo más de los que pasan y mueren en el escenario de la existencia. Esta clase excepcional de individuos siente un agudo dolor al contacto con la mediocridad de los otros seres, a tal punto que los hace encerrarse sobre sí mismos. La búsqueda de singularidad, de querer afirmarse en lo que son, los lleva a vivir la mayor parte de su vida recluidos en la soledad: "En toda persona profunda -afirma Valéry en su ensayo sobre Stendhal-, hay alguna virtud escondida que engendra incesantemente a un solitario" (Valéry, P., Estudios literarios, Madrid: Visor, 1995, p.140). La creación artística representa, a juicio de dicho autor, uno de los ámbitos intelectuales más óptimos y satisfactorios para el entrenamiento y cultivo de este egotismo. Sin embargo, sabe que su práctica en este campo de la creación tiene unos límites dados por el nivel de comunicación, de rechazo o de aceptación, de confrontación que pretenda establecer con su público (Luccisano, A., "Paul Valéry et la réception littéraire", en: Revue d'histoire littéraire de la France, v. LXXXVII, 6 (1987), pp. 1042-1043). 
otros yoes que serán los receptores de la obra. A fin de remarcar esta necesaria y decisiva comunicación, por la cual el artista está llamado a contener su impulso de soberanía puramente egotista, Valéry pone como referente lo que acontece en el plano de la creación literaria, hablando desde su propia experiencia creativa: "Cualquiera que sea el resultado de la empresa [literaria], nos obliga pues a una dependencia de los demás, y el espíritu y el gusto que les atribuimos se introducen así en lo íntimo del nuestro. Aun la más desinteresada, la que se cree más hosca, nos aleja insensiblemente del gran propósito de llevar nuestro yo al colmo de su deseo de poseerse, y sustituye por la consideración de lectores probables nuestra idea primera de un testigo inmediato o de un juez incorruptible de nuestro esfuerzo. Renunciamos sin saberlo a todo exceso de rigor o de perfección, a toda profundidad dificilmente comunicable; renunciamos a seguir todo lo que no condesciende, a concebir nada que no pueda imprimirse, pues es imposible andar en compañia hasta el fin del propio pensamiento, donde no se llega jamás sino por una suerte de abuso de soberanía interior"30.

Como ya lo advertimos, las obras artísticas son productos necesarios para el acrecentamiento del ser espiritual del hombre. Aun cuando materialmente han sido tomados como objetos inútiles -puesto que no están integrados de forma prioritaria en la lógica del beneficio que mueve la economía entre productores y consumidores-, históricamente dichos objetos han sido "creados y ofrecidos por los unos; acogidos y demandados por los otros" ${ }^{31}$, instaurándose con ello un mercado que podemos rastrear desde la antigüedad. Ahora bien, la justificación de esta demanda y oferta de obras artísticas (las cuales, junto con las demás producciones de carácter científico, filosófico e intelectual, constituyen el capital de la "economía poética") se basa en la profunda necesidad que tiene el hombre de excitar y satisfacer sensaciones, emociones y pensamientos que van más allá de los que están regulados por las determinaciones de la vida utilitaria. Teniendo en cuenta este particular requerimiento de la psicología humana, sobre el cual se afinca y extiende la dimensión de lo estético, es que el autor de El alma y la danza introduce la siguiente noción de valor respecto a la obra artística: "Decimos que una obra 'existe' o 'no existe', según ella nos haga o no sentir esta necesidad sensitiva o intelectual" 32 . Sin embargo, este reconocimiento o no que el público hace de la obra una vez ha sido vista y gustada, contiene aspectos singulares y sutiles que necesitan ser detallados.

\footnotetext{
${ }^{30}$ Valéry, P., Variedad II, p. 235.

${ }^{31}$ Valéry, P., OEuvres II, p. 1605.

32 Ibid.
} 


\section{El valor indeterminado de la obra de arte}

Valéry plantea que la producción y el consumo de la obra comporta el análisis "de los efectos que puede engendrar aquí o allá, en esta o aquella cabeza, en una u otra época"33. Ya hemos explicado el diametral contraste que el creador y el receptor mantienen en relación con la obra tomada, por parte del primero, como "el término" y, por parte del segundo, como "el origen de desarrollos"34. En conexión con este planteamiento, vale la pena precisar además que el consumo de la obra incorpora una actividad interpretativa que nunca puede alcanzar una última y definitiva determinación. Valéry habla de esta inaprehensibilidad definitiva del sentido de la obra, tomando como referente el estudio de Gustave Cohen en torno a su poema El cementerio marino. Después de escuchar el minucioso análisis de este experto sobre los elementos centrales que conforman el corpus del poema, sostiene, con pleno convencimiento, que una vez el productor entrega su obra a la luz pública, esta se convierte en una especie de objeto "del que cada cual puede servirse a su guisa y conforme sus medios"35. Eso significa que la apropiación de la obra artística por parte de cada consumidor genera una suerte de acto de re-creación alejado de cualquier forma de pasividad contemplativa ${ }^{36}$.

Christina Vogel acierta en indicar que más allá del análisis del valor definitivo que puede tener una obra, a Valéry le interesa resaltar su proceso de valorización: un aspecto que compromete la revisión de los mecanismos, condiciones y circunstancias en las cuales es producida su actualización ${ }^{37}$. Indudablemente, es desde esta perspectiva que cobra interés el estudio del efecto generado por la obra cuando es entregada al público. Es necesario recordar que en este proceso receptivo siempre existe el riesgo de que todo el esfuerzo intelectual y la inversión de tiempo que ha tomado la realización de la obra no sean plenamente reconocidos. Con el objeto de entender la desproporción entre los actos que determinan su realización (por los cuales se llega al estado de obra acabada), y la instantaneidad con que es captado su efecto, Valéry presenta la imagen de una enorme masa subida por partes a lo alto de una torre para luego ser arrojada desde allí, sin prestar atención al tiempo y trabajo que esto

\footnotetext{
${ }^{33}$ Valéry, P., Teoría poética y estética, p. 112.

34 Ibid., p. 113.

35 Valéry, P., Variedad II, p. 282.

${ }^{36}$ Cf. Jauss, H.R., Pequeña apología de la experiencia estética, Barcelona: Paidós, 2002, pp. 69-70.

37 Cf. Vogel, C., "Simone Weil et Paul Valéry: deux essais de penser la notion de valeur", en: Cahiers Simone Weil, Les écrits de Marseille I, v. XXXV, 3 (2012), pp. 373-374.
} 
ha tomado. Ahora bien, cuando se produce la conmoción deseada, a tal punto que las personas se sienten cautivadas por el vigor de la obra, por la gran cantidad de aciertos y sorpresas encontradas, el sentimiento de admiración lleva a que se dé una valoración de la obra e, incluso, de su creador. Desde esta perspectiva, el autor de El señor Teste muestra cómo el consumidor de obras artísticas asume también el rol de productor, en este caso, de valores. Esto lo explica de la siguiente manera: "Así es como el consumidor se convierte a su vez en productor: productor, primero, del valor de la obra y después, en virtud de una aplicación inmediata del principio de causalidad... se convierte en productor del valor del ser imaginario que ha hecho lo que admira"38.

De otra parte, Valéry señala que el proceso de valorización en el hombre viene determinado por la "sensibilidad afectiva" $39 \mathrm{y}$, en consecuencia, por su dimensión subjetiva. Esto significa que la actividad valorizante, en el fondo, escapa a cualquier fundamentación racional o prescripción objetiva, de modo que resulta estéril intentar explicar la naturaleza particular de todos los valores materiales e inmateriales del mundo ${ }^{40}$. Donde se hace más visible la imposibilidad de una pretendida determinación de valores objetivos es en el ámbito de las producciones inútiles de la mente. Especificamente, en el caso de las creaciones artísticas esta asignación de valor se problematiza mucho más ya que, a la luz del pensamiento de Valéry, el propósito de dichas obras consiste en satisfacer la necesidad de belleza en el hombre; una necesidad de tipo subjetivo que varía según la cultura y según la clase de individuo que la experimenta ${ }^{41}$. La argumentación de la belleza entendida como una forma

\footnotetext{
${ }^{38}$ Valéry, P., Teoría poética y estética, p. 115.

39 El proceso de valorización es explicado por Valéry desde el punto de vista fisiológico humano: "Sensibilidad afectiva - La que introduce la distribución o variación de la energía general y por consecuencia otorga los valores que son el transporte o el reintegro de energía de funcionamiento vital o de acción sobre uno de los sistemas funcionales" (Valéry, P., Cahiers I, p. 1199).

${ }^{40}$ Para Valéry, toda acción valorativa, desde su escala perceptiva más elemental (por medio de la cual el individuo comienza a establecer adecuaciones con la realidad), posee necesariamente un carácter fiduciario, esto es, una pauta acordada en la simple credibilidad (Cf. Zaccarello, B., "Le 'Moi' et le 'nous': limites et enjeux de l'épistémologie de l'histoire chez Paul Valéry", en: Pickering, R. (ed.), Paul Valéry 'Regards'sur l'histoire, Clermont-Ferrand: Presses Universitaires Blaise Pascal, 2008, pp. 81-82).

${ }^{41}$ La interpretación del fenómeno de la belleza en Valéry reposa sobre un discernimiento fisiológico. Específicamente, considera que la experiencia de la belleza acontece en el hombre ante la presencia sensible de un objeto, una imagen, un ser o una situación cualquiera que despierta, por su propio aspecto y forma de aparecer, el deseo "infinito" de su contemplación: "Hay belleza cuando la vista del objeto excita a verlo. Él contiene aquello que le permite repetirse indefinidamente". No obstante, a continuación precisa que esta experiencia es de carácter netamente privado: "Pero como la excitación es en una gran medida individual, la belleza de uno no es la de otro" (Valéry, P., Cahiers II, p. 935).
} 
de placer individual nos advierte, además, que su vivencia roza los lindes de la indeterminación y la incomunicabilidad. De aquí se sigue que los juicios de valor desprendidos de la belleza de un objeto cualquiera, más que aportar un grado de objetividad, aportan un grado de ambigüedad o indeterminación ${ }^{42}$. Esta atribución negativa sobre el valor de la belleza es así referida: "decir de un objeto que es bello es darle valor de enigma"43.

La contemplación de las obras pictóricas sirve como argumento para indicar que ningún discurso enunciativo restituye el grado de excitación despertado por una producción portadora de belleza: "La propiedad cardinal de ese bello cuadro consiste en excitar el sentimiento de no poder terminar con él por medio de un sistema de expresiones"44. De esta forma, cuanto más nos esforzamos en describir las cualidades de tal obra que nos impacta, más crece en nosotros el sentimiento de impotencia al pretender encontrar las palabras adecuadas para hacerlo ${ }^{45}$. El poeta francés aproxima la vivencia de la sensibilidad mística desarrollada por la teología negativa, con el propósito de explicar este sentimiento de inexpresividad que puede suscitar la contemplación de la belleza natural y artística ${ }^{46}$. En lo referente al carácter de inaprehensibilidad de la obra, mantiene que esto es lo que da pie para valorarla, ya sea como un "diamante" o como un simple "guijarro", por parte de los distintos públicos. El mundo poético sirve de referente para ejemplificar la apertura de ambas posibilidades, pues así como para algunas personas la poesía alcanza una "importancia infinita", para otras detenta, prácticamente, un "valor nulo"47. Por esta razón, adquiere el rasgo de una entidad enigmática y abstracta que, conforme a la naturaleza y disposición receptiva de los individuos, genera aprecio o desprecio, asombro o indiferencia, como también lo causa el misterio sobre la existencia de Dios.

\footnotetext{
${ }^{42}$ Valéry plantea la imposibilidad de que exista una única verdad de carácter universal que pueda fundamentar la validez de los juicios de gusto y, por lo tanto, que exista un juicio infalible para decidir sobre los verdaderos y los falsos placeres de orden estético, tal y como lo argumenta la estética kantiana ( $C f$. Brigante, A., Obstinado rigor: La teoría de la acción poética de Paul Valéry, Bogotá: Pontificia Universidad Javeriana, 2008, p. 58).

${ }^{44}$ Valéry, P., Cahiers II, p. 971.

${ }^{45}$ Recogiendo el enunciado de Valéry sobre la indeterminabilidad de las obras artísticas, Martin Seel corrobora que, en efecto, sea lo que sea que estas presenten, en tanto obras de arte siempre se resistirán a las pretensiones de una fijación conceptual que busca determinar de forma específica sus características (Cf. Seel, M., Estética del aparecer, Buenos Aires: Katz, 2010, p. 177).

${ }^{46} C f$. Gifford, P., "To Go to the Last Point. A la recherche d'une nouvelle définition du mysticisme", en: Gifford, P. y B. Stimpson (eds.), Paul Valéry. Musique, Mystique, Mathématique, París: Presses Universitaires de Lille, 1993, pp. 27-28.

${ }^{47}$ Valéry, P., Teoría poética y estética, p. 29.
}

$400 \quad{ }^{43}$ Valéry, P., Teoría poética y estética, p. 52. 


\section{Propuesta para el estudio crítico de la obra artística}

La hipótesis de que la obra artística posee un valor indeterminado plantea el problema de saber cómo puede ser reconocida su calidad e incentivado su consumo en el mercado artístico. Por su parte, Valéry cuestiona las teorias críticas que, partiendo de un orden causal, toman la personalidad real del autor y todos los eventos que rodean su existencia como aquello que explica, prioritariamente, el significado y el valor de cualquier obra. La censura a este método causalista (utilizado con amplitud en la historia de la literatura y del arte hecha hasta comienzos del siglo XX), obedece a que su forma de análisis está basada en una acumulación de datos biográficos y psicológicos completamente externos a los elementos, procedimientos, problemas y soluciones que permitirian explicar con mayor cabalidad el mérito del texto literario o del trabajo artístico ${ }^{48}$. Tomando como referente el mundo literario, Valéry precisa que la vida mental que da a luz un poema o una novela opera con un sistema funcional reflexivo en el que no tiene cabida, al menos de forma directa, la personalidad psíquica y biológica del escritor. De ahí que exprese: "La vida del autor no es la vida del hombre que él es"49. Con el objetivo de validar esta tesis, seguidamente nos ofrece un ejemplo: "acumulad todos los detalles que podáis sobre la vida de Racine y no lograréis el arte de componer sus versos" 50 . De esta manera nos está indicando que aun cuando se conozcan las circunstancias pormenorizadas sobre la vida de un escritor o artista, sus anécdotas y sus intimidades, todo ello no deja de ser más que una acumulación de hechos accesorios y desvios sin utilidad alguna para entender los actos que configuran su obra. En opinión del autor, el modo más acertado en el que puede efectuarse el estudio crítico de una obra es aprendiendo a desligar la personalidad psiquica y accidental del autor, prestando, por el contrario, atención a los distintos elementos y detalles que permiten rastrear las modalidades de actividad mental que intervinieron en la realización de la obra. Esta tarea interpretativa implica, a su vez, el intento de reconstruir los mecanismos, esfuerzos, principios e ideas que impulsaron y dieron forma a la creación.

Así, cuando Valéry expresa que podemos "estudiar la forma poética del Libro de Job o la del Cantar de los Cantares, sin la menor intervención de la biografia de sus autores, que son absolutamente desconocidos"51, está

\footnotetext{
48 Cf. Bémol, M., La méthode critique de Paul Valéry, Clermont-Ferrand: G. de Bussac, 1950, pp. 132-133.

${ }^{49}$ Valéry, P., Escritos sobre Leonardo da Vinci, p. 99.

50 Ibid.

51 Valéry, P., Variedad II, p. 225.
} 
proponiendo el desarrollo de una historia de la literatura que ya no otorga peso decisivo y protagónico al carácter biográfico y psicológico de los autores, sino al estudio de los componentes semiótico-estructurales de la obra ${ }^{52}$. A la luz de este nuevo enfoque, la calidad de una creación debe ser entendida a partir de las impresiones y sensaciones que ella misma arroja desde su singularidad expresiva. Por medio de esta vía es que efectivamente nos encontramos en la posibilidad de distinguir el tenor de las estructuras de la imaginación del escritor o artista, a la vez que la intencionalidad que guió todo su trabajo creativo ${ }^{53}$.

Tal fórmula estética es la que permite, en el caso del mundo literario, "elaborar una idea lo más exacta posible de las condiciones de existencia y de desarrollo de la literatura, un análisis de los modos de acción de este arte, de sus medios y de la diversidad de sus formas" 54 , señala Valéry. Dado que la literatura se deriva del lenguaje y se construye a partir de la aplicación de las propiedades específicas de este medio expresivo (tales como el sonido, el ritmo, la metáfora, la analogía, la sintaxis, los conceptos, etcétera), a la luz de esta teoria, el estudio de todo texto debe reparar en los modos de combinación intelectiva, emotiva y sensitiva con los que se fijan sus palabras. Ahora bien, lo cierto es que así debamos prestar atención a estas operaciones y reorganizaciones verbales al interior del texto, el autor nos advierte que su desciframiento literario ha de atender simultáneamente a la manera en que se integra en el marco de las convenciones culturales que han instituido patrones y géneros de escritura (época histórica, género literario, movimiento artístico, etcétera).

Cabe recalcar que este método de análisis tiene una aplicación similar para el estudio de las demás obras de arte, toda vez que, como lo advierte el propio Valéry, la capacidad de expresión artística del hombre no se agota exclusivamente a través de los signos del lenguaje hablado y escrito ${ }^{55}$. De hecho, el poeta francés reconoce que, en todas las obras de arte, en tanto que en ellas reside un acto de comunicación (de orden estético), hay una transmisión y

${ }^{52} C f$. Blüher, K.A., "La crítica literaria en Valéry y Borges", en: Revista Iberoamericana, v. LII, 135-136 (1986), pp. 447-461.

${ }^{53}$ William Marx recuerda que Valéry, junto con T.S. Eliot, valiéndose cada uno de sus propios argumentos, preparan la conformación de una crítica formalista que empieza a ser legitimada a partir de los años cincuenta en el marco de la nueva crítica literaria (Cf. Marx, W., Naissance de la critique moderne. La littérature selon Eliot et Valéry, Arras: Artois Presses Université, 2002).

${ }^{54}$ Valéry, P., Variedad II, p. 225.

${ }^{55}$ El propio Valéry anota que aun cuando la palabra es un medio de expresión de las ideas, esto no significa que sea el único canal de comunicación. A través del trabajo reflexivo de Leonardo da Vinci (logrado mediante la reflexión escrita, el lenguaje matemático y el dibujo), plantea la existencia de otros recursos de expresión por medio de los cuales el hombre transmite sus ideas y sentimientos (Cf. Valéry, P., Escritos sobre Leonardo da Vinci, pp. 129-132). 
recepción de signos portadores de un significado que busca ser interpretado. Instalado en el terreno de la semiótica, distingue este proceso comunicativo a través de la triada emisor-signo-receptor, la cual, desde el punto de vista de la economía poética, se corresponde directamente con la triada conformada por los conceptos ya referidos de productor-obra-consumidor ${ }^{56}$.

El decisivo papel que cumple la crítica en la creación de los valores artísticos y literarios, así como los efectos que provocan sus veredictos a favor o en contra de la consagración de una obra específica, son aspectos retenidos ampliamente por Valéry. Los reproches a reconocidos críticos literarios de su época (Taine, Nisard, Brunetière y Sainte Beuve), obedecen a la supuesta deficiente percepción y desconocimiento de ellos sobre la temática en que ejercen su función como destacados jueces. A tales tratadistas les censura la aplicación del modelo crítico que integra una acumulación de elementos biográficos, moralistas y anecdóticos, y que pretende identificar al hombre con el autor de las obras. En este sentido, todos los escritos de estos autores estarian desviándose de los verdaderos problemas estéticos que, a juicio suyo, urgen ser abordados.

Con no menos preocupación, el autor de Piezas sobre arte observa también la existencia de juicios literarios determinados por intereses apartados de un verdadero análisis riguroso de las obras; juicios que, en última instancia, delatan una falta de honestidad intelectual. En este caso, se trata de dictámenes aparecidos en artículos de prensa y revistas, en discursos, prefacios y ensayos diversos que están movidos por simples veleidades, por celos, orgullos y rivalidades entre un crítico y otro, por dogmatismos y pretensiones absurdas, por comparaciones inapropiadas entre un autor y otro, o entre una obra y otra: apreciaciones todas que representan una suma de doctas ignorancias ${ }^{57}$. Valéry siente una enorme molestia por las opiniones inexactas o desvirtuadas que desconocen el verdadero problema literario y artístico que impulsó la elaboración

\footnotetext{
56 Tal concordancia entre ambas triadas es la que le concede a Valéry la posibilidad expresar en términos semióticos, por ejemplo, el complejo y diferenciado enlace que existe entre el poeta, el poema y el público que escucha o lee el poema: "La poesia es un arte del lenguaje. El lenguaje es una combinación de funciones heteróclitas, coordinadas en reflejos adquiridos mediante un uso que consiste en tanteos innumerables. Los elementos motores, auditivos, visuales, mnemónicos, forman grupos más o menos estables; y sus condiciones de producción, de emisión, así como los efectos de su recepción son sensiblemente diferentes según las personas” (Valéry, P., Teoria poética y estética, p. 205).

${ }_{57}$ Así lo demuestra, sacando a la luz las supuestas ideas que gobiernan la autoconciencia de dicha clase de jueces: "Resumen de la crítica conocida (Nisard, Beuve, Brunetière, Lemaitre, etc.) - Esto me place. Esto no me place... - Apuesto a que este libro estará totalmente olvidado en diez años. Lo apuesto. Lo deseo y comienzo por destruirlo hoy, ya que quiero ganar mi apuesta. ... -Voy a probaros que lo que os place no os place..." (Valéry, P., Cahiers II, p. 1177).
} 
de la obra. Motivado por razones éticas de respeto, sugiere que las valoraciones subjetivas hacia una obra o un autor no tienen por qué aparecer publicadas. Frente a este tipo de apreciaciones, en entrevista con Frédéric Lefèvre, sugiere ser más prudentes: "Si un libro os aburre, ¿qué hay de más simple que cerrar un libro? Si una reputación os irrita, basta pensar que ese mal pasará, que la moda nos eleva, nos baja, nos acaricia, nos abandona, por el simple juego de las cosas simples, y que no podemos alli hacer nada" 58 .

No podemos ignorar que dicho ataque al antiguo canon de la crítica literaria se vincula directamente con la denuncia de la crisis global de la literatura francesa de finales del siglo XIX y comienzos del XX en aspectos cruciales como su objeto, sus valores, su función y discurso crítico ${ }^{59}$. Entre otras cosas, Valéry estima que dichos discursos críticos, al estar apartados de los verdaderos intereses de la realidad literaria, afectan la recepción y consumo que moviliza su mercado. Sin embargo, esto no le impide encomiar la labor honrada de aquellos otros aficionados y conocedores que desde mucho antes, y también en su época, asumieron una actitud de análisis honesta frente a las obras que tenían ante sí. Esta clase de individuos expertos constituye un claro referente de consumidores que, a su vez, son productores de valores no solo relacionados con la calidad de las obras, sino también con la calidad de los autores que las han producido. Al evocarlos, el autor de La joven parca puntualmente destaca de ellos su capacidad para convertir "en valor sólido"60 y, por lo tanto, en criterio de análisis confiable -como lo ofrece el valor oro- todo juicio emitido sobre la obra que leen, escuchan o ven con absoluta e imparcial entrega.

A la luz de estas formulaciones podemos colegir que los buenos críticos, ya sean literarios o de arte, están llamados a elaborar sus juicios atendiendo al análisis de las resistencias y los esfuerzos mentales que participaron en la elaboración de la obra. Es así como lo corrobora Valéry: "El objeto de un auténtico crítico debiera consistir en descubrir qué problema (consciente o inconscientemente) se ha planteado el autor e investigar si lo ha resuelto o no"61. Esta indicación adquiere una mayor relevancia al entender el decisivo papel que esta clase de intermediadores cumple en la creación de los valores artísticos y literarios, y en los efectos que pueden provocar sus veredictos a favor o en contra de la consagración de una obra específica.

${ }^{58}$ Lefèvre, F., Entretiens avec Paul Valéry, Paris: Le Livre, 1926, p. 26.

${ }^{59}$ Cf. Marx, W., Naissance de la critique moderne. La littérature selon Eliot et Valéry.

${ }^{60}$ Valéry, P., Miradas al mundo actual, p. 202.

${ }^{61}$ Valéry, P., Tel Quel I, Barcelona: Labor, 1977, p. 170. 


\section{Conclusión}

Después de haber hecho este recorrido reflexivo, hemos podido observar que la idea del arte en Valéry va más allá de unas argumentaciones de orden puramente estético. Es innegable que su estudio sobre la obra artística considerada como objeto de cambio introduce una aguda mirada que facilita la comprensión de las dificultades y paradojas que complejizan el desarrollo y la asimilación del arte como capital cultural a partir de la primera mitad del siglo XX. Una de las cosas más interesantes planteadas por dicho pensador consiste en proponer una desmitificación del valor netamente simbólico del arte, dando paso a una comprensión más objetiva de su sistema de producción y recepción integrado a las leyes del sistema económico. Con ello, además, podemos observar una critica a las teorias puras que, desde el orden de lo estético y semiótico, toman el arte como una producción intelectual destinada solo para la apropiación simbólica y desinteresada, irreductible a las dinámicas y necesidades materiales de la economía. Valéry comprende que el valor del arte no solo puede entenderse en términos de su valor de uso (el cual viene establecido por el beneficio espiritual y cultural prestado por cada obra artística), sino también en términos de su valor de cambio (algo concretado por la posibilidad de que la producción artística pueda ser permutada por otra mercancía o por dinero, y que involucra ya el análisis de su complejo mercado). Sin embargo, tal apreciación no le hace perder de vista que toda obra, aun cuando deba ser tomada como una mercancía que posee un valor material, es ante todo un producto intelectual y cultural, poseedor de una indeclinable entidad simbólica, cuyo valor escapa a cualquier intento de simplificación definitiva de la racionalidad teórica y utilitaria que gobierna el mundo. Sin duda alguna, es aquí donde la figura del crítico ocupa un papel fundamental como orientador de los gustos estéticos. Especialmente, cuando la creciente consolidación de la industria cultural y el consumo masificado de nuevas producciones artísticas, al igual que el incremento de un público sin claras ideas de consumo y selección cualitativa, tienden a hacer perder de vista la necesaria distinción e independencia entre el valor económico y el valor simbólico de las obras.

Recibido: 01/12/2015

Aceptado: 25/08/2017 


\section{Bibliografia}

Acha, J., Crítica del Arte. Teoria y práctica, México D. F.: Trillas, 1992.

Auden, W.H., El arte de leer. Ensayos literarios, Barcelona: Lumen, 2013.

Bémol, M., La méthode critique de Paul Valéry, Clermont-Ferrand: G. de Bussac, 1950.

Blüher, K.A. "La crítica literaria en Valéry Borges", en: Revista Iberoamericana, 135-136

(1986), pp. 447-461. https://doi.org/10.5195/REVIBEROAMER.1986.4214

Brigante, A., Obstinado rigor: La teoría de la acción poética de Paul Valéry, Bogotá: Pontificia Universidad Javeriana, 2008.

Bucher, J., Paul Valéry y la nueva crítica literaria, Cali: Universidad del Valle, 1979.

Faulstich, W., "La literatura como mercancía. Sobre el efecto fascinador de la comercialización de la literatura en la sociedad burguesa", en: Wischer, E. (dir.), Historia de la literatura. Vol. V. La Edad Burguesa: 1830-1914, Madrid: Akal, 1993.

Gifford, P., "To Go to the Last Point. A la recherche d'une nouvelle définition du mysticisme", en: Gifford, P. y B. Stimpson (eds.), Paul Valéry. Musique, Mystique, Mathématique, Paris: Presses Universitaires de Lille, 1993.

Hilton, R. y M. Dobb, La transición del feudalismo al capitalismo, Barcelona: Crítica, 1977. Hytier, J., La poétique de Valéry, Paris: Armand Colin, 1970.

Jauss, H.R., Pequeña apología de la experiencia estética, Barcelona: Paidós, 2002.

Lefèvre, F., Entretiens avec Paul Valéry, Paris: Le Livre, 1926.

Luccisano, A., "Paul Valéry et la réception littéraire", en: Revue d'Histoire littéraire de la France, 6 (1987), pp. 1042-1052.

Marx, K., El Capital. Crítica de la economía política, vol. 1, México: Fondo de Cultura Económica, 1974.

Marx, W., Naissance de la critique moderne. La littérature selon Eliot et Valéry, Arras: Artois Presses Université, 2002.

Moulin, R., Le marché de la peinture en France, Paris: Minuit, 1967.

Seel, M., Estética del aparecer, Buenos Aires: Katz, 2010.

Schmidt-Radefeldt, J., Paul Valéry linguiste dans les Cahiers, Paris: Klincksieck, 1970.

Valéry, P., Vues, Paris: La Table Ronde, 1948.

Valéry, P., Miradas al mundo actual, Buenos Aires: Losada, 1954.

Valéry, P., Variedad II, Buenos Aires: Losada, 1956.

Valéry, P., OEuvres II, Paris: Gallimard, 1960.

Valéry, P., Cahiers I, Paris: Gallimard, 1973.

Valéry, P., Cahiers II, Paris: Gallimard, 1974.

Valéry, P., Tel Quel I, Barcelona: Labor, 1977.

Valéry, P., Escritos sobre Leonardo da Vinci, Madrid: Visor, 1987.

Valéry, P., Teoría poética y estética, Madrid: Visor, 1990.

Valéry, P., Estudios literarios, Madrid: Visor, 1995.

Vogel, C., "Simone Weil et Paul Valéry: deux essais de penser la notion de valeur", en: Cahiers Simone Weil, Les écrits de Marseille I, Tome XXXV - n. ${ }^{\circ}$ 3, 2012.

Walras, L., Éléments d'économie politique pure, ou Théorie de la richesse sociale, Paris: R. Pichon et R. Durand-Auzias, 1926.

Zaccarello, B., "Le 'Moi' et le 'nous': limites et enjeux de l'épistémologie de l'histoire chez Paul Valéry”, en: Pickering, R. (ed.), Paul Valéry 'Regards' sur l'histoire, ClermontFerrand: Presses Universitaires Blaise Pascal, 2008. 